\title{
Intractable Childhood Epilepsy and Maternal Fatigue
}

\author{
Mohammed M.S. Jan
}

\begin{abstract}
Background: Mothers of children with intractable epilepsy are generally stressed and experience more emotional problems. Fatigue may affect their productivity, social interactions, and their ability to adequately take care of their children. The objectives were to examine the relationship between intractable childhood epilepsy and maternal fatigue, and explore possible contributing factors. Methods: Sixty-four consecutive mothers of children with intractable epilepsy were identified prospectively. Exclusion criteria included degenerative/metabolic disorders or life threatening illness, such as brain tumors. Fatigue was measured using a standardized 11-item questionnaire, which has been revalidated in an Arabic speaking population. Results: Mothers' ages were 24-45 years (mean 34) and ages of their epileptic children were 1-15 years (mean 6.7). Most children (64\%) had epilepsy for $>2$ years, were on $>1$ antiepileptic drug (AED) (72\%), and had daily seizures (47\%). Thirty-four (54\%) of the children had motor deficits and $83 \%$ had mental retardation (severe in $41 \%$ ). Twenty-eight (44\%) mothers were fatigued. Factors associated with increased maternal fatigue included child's age $<2$ years $(\mathrm{p}=0.01)$, cryptogenic epilepsy $(\mathrm{p}=0.03)$, and severe motor deficits $(\mathrm{p}=0.04)$. Factors associated with lowered fatigue included performing regular exercise $(\mathrm{p}=0.006)$, lack of mental retardation $(\mathrm{p}=0.01)$, seizure control $(\mathrm{p}=0.05)$, using one $\operatorname{AED}(\mathrm{p}=0.002)$, infrequent ER visits $(\mathrm{p}=0.005)$, and lack of recent hospitalization ( $\mathrm{p}=0.005)$. Conclusions: Mothers of children with intractable epilepsy are increasingly fatigued. Several correlating factors were identified, mostly related to seizure control, mental and physical handicap. Strategies to manage the problem include proper education, seizure control, participation in regular exercise, social support, and psychological counseling.
\end{abstract}

RÉSUMÉ: Épilepsie de l'enfance réfractaire au traitement et fatigue maternelle. Contexte : Les mères d'enfants présentant une épilepsie réfractaire au traitement éprouvent un haut niveau de stress et présentent plus de problèmes émotifs. La fatigue peut affecter leur productivité, leurs interactions sociales et leur capacité à prendre soin adéquatement de leurs enfants. Cette étude avait pour objectif d'examiner la relation entre l'épilepsie réfractaire de l'enfance et la fatigue maternelle et d'explorer les facteurs qui y contribuent. Méthodes : Soixante-quatre mères d'enfants atteints d'épilepsie réfractaire ont été identifiées consécutivement de façon prospective. Les mères d'enfants atteints de maladies dégénératives ou métaboliques ou de maladies potentiellement fatales comme les tumeurs cérébrales étaient exclues. La fatigue était mesurée au moyen d'un questionnaire standardisé de 11 items qui a été revalidé dans la population de langue arabe. Résultats : Les mères étaient âgées de 24 à 45 ans (âge moyen de 34 ans et l'âge moyen de leurs enfants épileptiques était de 1 à 15 ans (âge moyen de 6,7 ans). La plupart des enfants (64\%) étaient épileptiques depuis plus de 2 ans, prenaient plus d'un médicament antiépileptique (72\%) et avaient des crises quotidiennes (47\%). Trente-quatre (54\%) des enfants avaient des déficits moteurs et $83 \%$ avaient un retard mental qui était sévère chez $41 \%$. Vingt-huit (44\%) des mères étaient fatiguées. Les facteurs associés à une fatigue maternelle plus sévère étaient les suivants : un enfant de moins de 2 ans $(p=0,01)$, une épilepsie cryptogénique $(p=0,03)$ et des déficits moteurs sévères $(\mathrm{p}=0,004)$. Les facteurs associés à une fatigue moindre étaient l'activité physique régulière $(\mathrm{p}=0,006), \mathrm{l}$ 'absence de retard mental $(\mathrm{p}=0,01)$, le contrôle des crises $(p=0,05)$, l'utilisation d'un seul antiépileptique $(p=0,002)$, des visites peu fréquentes au service d'urgences ( $p=0,005)$ et l'absence d'hospitalisation récente $(\mathrm{p}=0,005)$. Conclusions : Les mères des enfants atteints d'épilepsie réfractaire éprouvent de plus en plus de fatigue. Plusieurs facteurs qui y sont corrélés ont été identifiés, surtout en rapport avec le contrôle des crises et le handicap mental et physique. Parmi les stratégies pour gérer le problème citons une éducation adéquate, le contrôle des crises, l'activité physique régulière, le soutien social et la consultation en psychologie.

Can. J. Neurol. Sci. 2006; 33: 306-310

Seizures are the most common cause of referral to pediatric neurology clinics and represent an important cause of pediatric morbidity. Epilepsy, defined as recurrent unprovoked seizures, is a common neurological disorder in children with a frequency of four to eight cases per 1000 children. ${ }^{1}$ In Saudi Arabia, inherited neurological disorders, including epilepsy and genetic epilepsy syndromes, are more common as a result of the high rate of consanguineous marriages. ${ }^{2}$ Intractability in childhood epilepsy has been associated with motor, cognitive, and behavioral problems and impaired psychosocial development. ${ }^{3,4}$ Therefore, these children have a high potential for long-term disability and difficulties in adjusting to school and community. ${ }^{5}$ Recurrent seizures also increase the risk of injury and even death. ${ }^{6-8}$ Parents, particularity mothers, are frequently faced with the

From the Department of Pediatrics, King Abdulaziz University Hospital, Jeddah, Kingdom of Saudi Arabia.

Received SEPTEMber 6, 2005. ACCEPTED in FinAl FORM March 8, 2006. Reprint requests to: Mohammed M.S. Jan, Department of Pediatrics (Neurology), King Abdulaziz University Hospital, P.O. Box 80215. Jeddah 21589, Kingdom of Saudi Arabia. 
physical and emotional burden of dealing with the epileptic child.

In general, fatigue is the seventh most common complaint seen at primary health care centers. ${ }^{9}$ Fatigue appears to be a cultural 'idiom of distress', a way of expressing anxiety or depression. ${ }^{10}$ Camfield et $\mathrm{al}^{11}$ found that parents of epileptic children generally were more stressed, had lower self-esteem, and experienced more emotional problems. This is in agreement with other authors who found the mothers of epileptic children to experience more overall stress and disruption in their attachment to their child. ${ }^{12}$ These mothers also frequently perceived their epileptic children as more distractible/hyperactive, less adaptive, and more demanding than did control mothers. ${ }^{12}$ Maternal fatigue may affect their productivity, social interactions, and their ability to adequately take care of their children. ${ }^{13}$ These issues are frequently ignored and had not been studied systematically.

The objectives of this study were to examine the relationship between intractable childhood epilepsy and maternal fatigue, and explore possible contributing factors to increased maternal fatigue. Fatigue is measured using a standardized questionnaire regarding both the physical and mental symptoms of fatigue. ${ }^{14}$ This questionnaire has been translated and revalidated in our Arabic speaking population. ${ }^{15}$ I hypothesized that many mothers of epileptic children suffer from fatigue symptoms as a result of multiple factors related to their child's disease, such as seizure control, physical and mental handicap, independent of other socio-demographic variables.

\section{METHODS}

The mothers of a series of consecutive children with intractable epilepsy were identified prospectively from June 1, 2004 to May 31, 2005. Families were identified through referrals and consultations to the pediatric neurology service at King Abdulaziz University Hospital and King Faisal Specialist Hospital and Research center (KFSH\&RC), both in Jeddah, Saudi Arabia. King Abdulaziz University Hospital is the main teaching center of the western region in collaboration with KFSH\&RC. Both are multi-specialty adult and pediatric hospitals providing tertiary medical care for most of the regional population of western Saudi Arabia. Intractable epilepsy was defined as recurrent seizures that failed to respond to at least three antiepileptic drug trials singly or in combination, despite using maximum doses or doses resulting in therapeutic drug levels. ${ }^{16}$ Children with progressive central nervous system disease (degenerative or metabolic disorders) or life threatening illness (brain tumors) were excluded. In hospital children were not included to eliminate maternal fatigue related to hospital stay. The study design and questionnaires were approved by KFSH\&RC ethics committee.

All participating mothers signed a written informed consent. They were assured that taking part in the study was voluntary and that their identity would remain anonymous. A structured 33item questionnaire was designed to examine the family demographic characteristics, details of the child's epilepsy, and any associated physical or mental disability (Table 1). The mothers were asked about smoking, regular exercise, and availability of home-helpers. A Likert scale item ${ }^{17}$ was included to examine whether the mother was able to go out of the house

\section{Table 1: List of factors that were assessed to correlate with} maternal fatigue

\section{Child Related Factors}

1- Child's age**

2- Gender

3- School grade

4- Nationality

5- Number of brothers and sisters and their ages

6- Diagnosis

7- Mental retardation (mild, moderate, or severe)**

8- Physical handicap such as cerebral palsy (mild, moderate, or severe)**

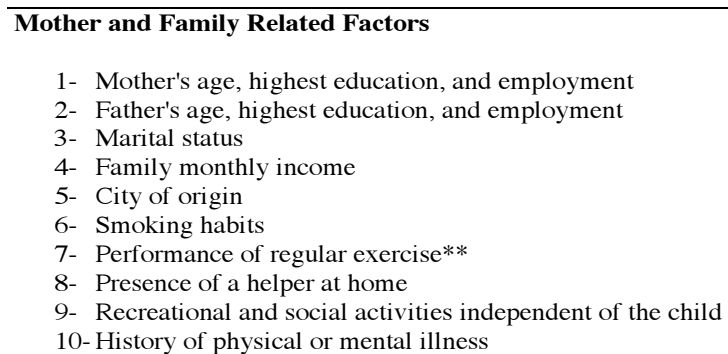

\section{Epilepsy Related Factor}

1- Underlying Etiology**

2- Epilepsy diagnosis

3- Age of onset

4- Seizure types

5- Seizure count (daily, weekly, monthly, or longer)

6- If seizure free, for how long?**

7- Past and current antiepileptic drugs

8- Number of current antiepileptic drugs**

9- Number of hospital admissions over the last 6 months**

10- Number of clinic visits over the last 6 months

11- Number of emergency room visits over the last 6 months**

**Factors significantly associated with maternal fatigue $(\mathrm{P}<0.05)$ detailed in Table 4

for recreation or socialization without the child. Response categories to the Likert scale item were: 1) never, 2) somewhat, 3) most of the time, and 4) all the time. The second questionnaire was a standardized fatigue scale (Table 2). It provided a scale of fatigue from 0 to 11 and covered two domains, physical and mental fatigue. ${ }^{14}$ The scale had been translated into Arabic and revalidated in an Arabic speaking population. ${ }^{15}$ Mothers were considered fatigued if they scored 5 or higher on the fatigue scale $^{14,15}$ The author conducted all the interviews during an outpatient clinic visit. The data was tabulated using Epi Info, version $6,{ }^{18}$ and the results were examined by Chi-square statistics to identify the magnitude of significant associations when present. A p-value less than 0.05 was considered statistically significant.

\section{RESUlts}

Sixty-four mothers were interviewed during the study period. Socio-demographic variables of the included families are summarized in Table 3. Most mothers were of Saudi Arabian nationality (88\%), married (91\%), and housewives (92\%). Only four $(6 \%)$ of the mothers smoked regularly and $14 \%$ and $16 \%$ 
Table 2: Standard fatigue scale (0-11)

\begin{tabular}{l|l}
\hline Physical symptoms & Bimodal response system \\
\hline & \\
1. Do you have problems with tiredness? & Less than usual (0) \\
2. Do you need to rest more? & Same as usual (0) \\
3. Do you feel sleepy or drowsy? & More than usual (1) \\
4. Do you have problems starting things? & Much more than usual (1) \\
5. Are you lacking in energy? & \\
6. Do you have less strength in your muscles? & \\
7. Do you feel weak? & \\
& \\
\hline Mental symptoms & Bimodal response system \\
\hline & \\
8. Do you have difficulty concentrating? \\
9. Do you have problems thinking clearly? & Less than usual (0) \\
10. Do you make slips of the tongue when speaking? & More than usual (1) \\
11. Do you have problems with your memory? & Much more than usual (1) \\
\hline
\end{tabular}

had suffered from a medical or psychiatric illness, respectively. Most of the families (66\%) lived in the Jeddah area and 57\% had a helper at home. Eighteen (29\%) families had a young infant at home, and the total number of their other children ranged from 1-9 (mean 3.7, SD 1.9). Only 14 (23\%) of the mothers reported participating in regular physical exercise. Regarding the Likert scale item, only $10 \%$ reported going out of the house regularly for recreation without the child and $42 \%$ reported that this never happens.

The ages of the epileptic children were 1-15 years (mean 6.7, SD 4.5 ) with $59 \%$ being males. The epilepsy was symptomatic in $58 \%$, idiopathic in $14 \%$, and cryptogenic in $28 \%$. Mental retardation was associated in $53(83 \%)$ children, which was severe in $41 \%$. Thirty-four (54\%) children had motor deficits including cerebral palsy, which was severe in 22 (34\%). Only 12 (20\%) children were enrolled in a regular school program. The epilepsy was intractable with duration of more than two years in $64 \%$, multiple seizure types in $31 \%$, and requiring two or more antiepileptic drugs (AED) in $46(72 \%)$ children. Many children (47\%) had daily seizures and only $18(28 \%)$ were seizure free for more than three months at the time of interview. Over the prior six months, $32 \%$ were admitted to hospital (mean 1.8 times), $45 \%$ had emergency room visits (mean 2.8 times), and $79 \%$ had several clinic visits (mean 4.6).

Regarding maternal fatigue, 28 (44\%) of the mothers were fatigued (5-11 on the fatigue scale). Several factors were significantly associated with lowered maternal fatigue scores including performing regular exercise, lack of mental retardation, seizure control, use of one AED, infrequent ER visits, and lack of hospital admissions in the prior 6 months (Table 4). Factors associated with increased maternal fatigue scores included younger child's age (infancy), cryptogenic epilepsy, and severe motor deficits (Table 4, Figure). The number of ongoing seizures did not affect the maternal fatigue severity scale. As well, other socio-demographic variables, such as parents' ages, occupations, number of children, or income, did not have a statistically significant impact. Other epilepsy related variables (duration or type) also had no statistically significant correlations.

\section{Discussion}

This study documented that mothers of children with intractable epilepsy are increasingly fatigued. Fatigue or "total body pain' is a common presentation symbolizing a problem, which is rarely physical but often related to stress at home or general discomfort. Fatigue correlates with major depression, generalized anxiety disorder, beliefs of ill health, and stressful life events. ${ }^{19,20}$ The prevalence of fatigue in this study (44\%) is much higher than the $10 \%$ reported by attendees of general practice clinics using the same questionnaire. ${ }^{21} \mathrm{~A}$ recent study from our region suggested that fatigue symptoms might be higher when compared with western studies. ${ }^{10}$ However, studies in intractable childhood epilepsy are lacking. Many women complain of tiredness related to childcare and family responsibilities, with stress and overwork adding to the prevalence of conditions such as chronic fatigue syndrome. ${ }^{22}$ In Saudi Arabia, further cultural pressures add to the problem. Mothers are frequently the main responsible parent for raising and looking after the children with limited input from the fathers. The opposing influences of traditional culture with extremely rapid social change, affluence with high illiteracy, substantial

Table 3: Some socio-demographic characteristics of the study families $(n=64)$

\begin{tabular}{l|l}
\hline Demographics & Results in the study sample \\
\hline \hline Mother's Age & $24-45$ years (mean 34, SD 6) \\
\hline Father's Age & $26-70$ years (mean 41, SD 10) \\
\hline Parent's Education & $4 \%$ fathers / 19\% mothers \\
1- None & $59 \%$ fathers / 64\% mothers \\
2- School grade & $37 \%$ fathers / 17\% mothers \\
3- College or university & $1 \%$ \\
\hline Father's Employment & $7 \%$ \\
1- Unemployed & $55 \%$ \\
2- Professional & $12 \%$ \\
3- Regular / office work & $10 \%$ \\
4- Military & $6 \%$ \\
5- Labor worker & $10 \%$ \\
6- Teacher & $3.5 \%$ \\
7- Other & $23 \%$ \\
\hline Family's Monthly Income & $28 \%$ \\
1- < 1000 SR (267 USD) & $23.5 \%$ \\
2- 1000-2999 (267-799) & $22 \%$ \\
3- 3000-6999 (800-1867) & \\
4- 7000-10,000 (1868-2667) & 5- > 10,000 (2668)
\end{tabular}


Table 4: Factors significantly associated with maternal fatigue

\begin{tabular}{|c|c|c|c|}
\hline Variable & $\begin{array}{c}\text { Fatigue } \\
\text { Number } / \text { Total }(\%)\end{array}$ & $\begin{array}{c}\text { No Fatigue } \\
\text { Number / Total }(\%)\end{array}$ & P value \\
\hline \multicolumn{4}{|l|}{ Child Related Factors } \\
\hline Child's age less than 2 years & $10 / 14(71 \%)$ & $4 / 14(29 \%)$ & 0.01 \\
\hline No mental retardation & $1 / 11(9 \%)$ & $10 / 11(91 \%)$ & 0.01 \\
\hline Severe motor deficits & $15 / 22(68 \%)$ & $7 / 22(32 \%)$ & 0.04 \\
\hline \multicolumn{4}{|l|}{ Mother Related Factors } \\
\hline Perform regular exercise & $2 / 14(14 \%)$ & $12 / 14(86 \%)$ & 0.006 \\
\hline \multicolumn{4}{|l|}{ Disease Related Factor } \\
\hline Infrequent ER visits $(<2)$ over the last 6 months & $19 / 49(39 \%)$ & $30 / 49(61 \%)$ & 0.002 \\
\hline On only one antiepileptic drug & $2 / 18(11 \%)$ & $16 / 18(89 \%)$ & 0.005 \\
\hline Cryptogenic epilepsy & $12 / 18(67 \%)$ & $6 / 18(33 \%)$ & 0.03 \\
\hline Complete seizure control for 3 months or longer & $4 / 18(22 \%)$ & $14 / 18(78 \%)$ & 0.05 \\
\hline No hospital admissions over the prior 6 months & $12 / 36(33 \%)$ & $24 / 36(67 \%)$ & 0.05 \\
\hline
\end{tabular}

households with many children and servants are peculiar to our region. ${ }^{10}$

Many factors have been shown to be associated with fatigue. History of psychological problems, social difficulties, chronic illness and certain drugs are known to be causes of fatigue. Inactivity and obesity contribute to the problem, and other aspects of lifestyle such as smoking and alcohol ingestion may have an adverse effect on general well-being. ${ }^{23}$ In this study, factors significantly associated with lowered maternal fatigue scores included performing regular exercise, lack of mental retardation, seizure control, using one AED, infrequent ER visits,

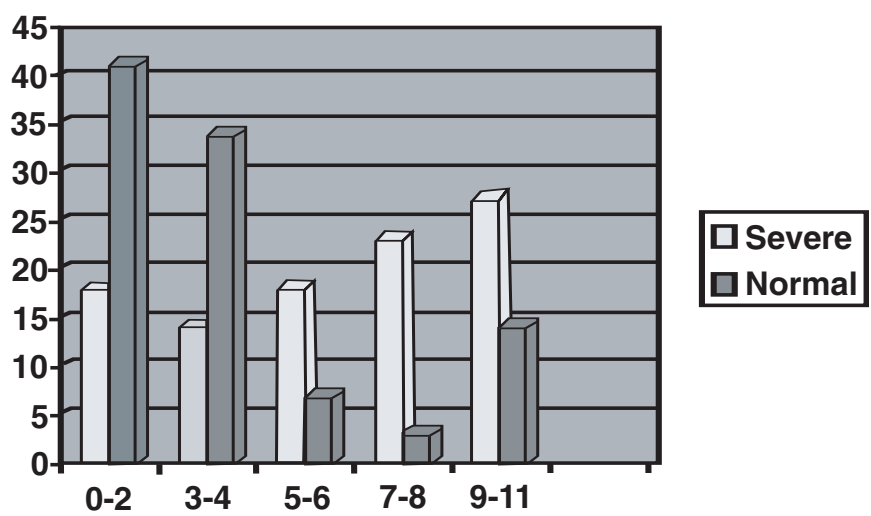

Figure: Severity of maternal fatigue in two groups of children with intractable epilepsy and severe motor deficits and normal motor function, shown as percentages. and lack of recent hospitalization. Only $23 \%$ of the mothers in this study exercised regularly, which is lower than western figures. ${ }^{23}$ The positive effect of regular exercise on fatigue symptoms confirms the findings of previous studies. ${ }^{22,23}$ Regarding mental retardation, Shore et $\mathrm{al}^{24}$ found child behavioral problems to be the strongest predictor of maternal depressive symptoms. We found a reversed correlation with normal cognition being associated with less fatigue. As expected, seizure control, less medications and hospital visits were all associated with less maternal fatigue; however, other epilepsy related variables (duration or type) had no statistically significant correlations. Interestingly, if the child had ongoing seizures, the actual frequency did not seem to matter in terms of maternal fatigue severity scale.

Factors associated with increased maternal fatigue scores in this study included younger child's age (infancy), cryptogenic epilepsy, and severe motor deficits. Maternal fatigue is prevalent in the postnatal period because of increased need for support and transition to motherhood..$^{25}$ Epilepsy adds to this stress making the infancy period highly associated with maternal fatigue. There were four children born to the study subjects on average. Consequently, there was a longer gap in years between the youngest and oldest child, resulting in many years of parenting. The other factor associated with child-care is the availability of servants to help with household duties. It was surprising that having a servant did not decrease fatigue, suggesting that the mothers continued to carry the physical and emotional burden of the epileptic child. Regarding the epilepsy etiology, it is likely that the uncertainties about the diagnosis in the cryptogenic group resulted in increased emotional stress. In fact, Sheeran et $\mathrm{al}^{26}$ found that maternal resolution vs. nonresolution of diagnosis 
was related to parenting stress and marital satisfaction. Other socio-demographic variables, such as parent's ages, occupation, number of children, or income, did not have a statistically significant impact possibly related to the relatively small study sample. However, the sample is representative of various sectors of our community with variations of education, occupation and income (Table 3). Some authors found significant associations between maternal depressive symptoms and family income or satisfaction with family relationships, ${ }^{24}$ while others found no effect of age and marital status on fatigue symptoms. ${ }^{22}$ Smoking was not associated with fatigue, as found in previous Western studies. However, only a small number of mothers smoked regularly (6\%), precluding accurate conclusions. Fatigue was not associated with maternal history of medical or psychiatric illness; however, the numbers in each group were small. This is in contrast to other studies where fatigue was associated with certain medical and psychiatric conditions. ${ }^{23}$

In summary, mothers of children with intractable epilepsy are increasingly fatigued. Factors associated with increased maternal fatigue scores included younger child's age (infancy), cryptogenic epilepsy, and severe motor deficits. Factors associated with lowered maternal fatigue scores included performing regular physical exercise, lack of mental retardation, seizure control, using one AED, infrequent ER visits, and lack of recent hospitalization. As the prevalence of fatigue in this population is high, strategies to manage the problem need to be developed. This is critical given that fatigue can affect their productivity, family, and social interactions. ${ }^{13,27}$ A recent study found that the attitudes of mothers of epileptic children differed significantly from those of healthy children in terms of inappropriate bringing. ${ }^{27}$ As well, maternal fatigue may affect the proper medical management as it can influence confidence in the provided treatments and compliance with medications. ${ }^{28}$ In addition to proper medical management, solutions to increased maternal fatigue should include participation in regular physical exercise, increased social support including going out more often without the child (respite), and psychological counseling. In many developing counties, there is a lack of patient and family education in many aspects relating to epilepsy and fatigue symptoms. ${ }^{29}$ Education of the parents about the symptoms of epilepsy and early recognition of fatigue is an important step in finding possible solutions before the establishment of further psychological sequele.

\section{ACKNOWLEDGMENT}

I thank Dr. Nawal Bahassan and Dr. El-Sayed Ali for contacting some of the study families. I also thank Dr. Amira AlBuhairi for the statistical assistance and Prof. John Girvin for critically reviewing the final manuscript.

\section{REFERENCES}

1. Annegers JF. Epidemiology and genetics of epilepsy. Neurol Clin. 1994;12:15-29.

2. El-Hazmi MAF, Warsy AS. Genetic disorders among Arab populations. Saudi Med J. 1996;17:108-23.

3. Austin JK, Smith S, Risinger MW, McNehs AM. Childhood epilepsy and asthma comparison of quality of life. Epilepsia. 1994;35:608-15.

4. Farwell JR, Dodrill CB, Batzel LW. Neuropsychological abilities of children with epilepsy. Epilepsia. 1985;26:395-400.
5. Kotagal P, Rothner AD, Erenberg G, Cruse RP, Wyllie E. Complex partial seizures of childhood onset. Arch Neurol. 1987;44:117780.

6. Baker GA, Jacoby A, Buck D, Stalgis C, Monnet D. Quality of life of people with epilepsy: a European study. Epilepsia. 1997;38(3):353-62.

7. Buck D, Baker GA, Jacoby A. Patient's experiences of injury as a result of epilepsy. Epilepsia. 1997;38:439-44.

8. Harvey AS, Nolan T, Carlin JB. Community-based study of mortality in children with epilepsy. Epilepsia. 1993;34:597-603.

9. McWhinney IR. A Textbook of Family Medicine. 2nd ed. New York: Oxford University Press; 1989.

10. McIlvenny S, DeGlume AM, Elewa M, Fernandez OT, Dormer P. Factors associated with fatigue in a family medicine clinic in the United Arab Emirates. Family Practice. 2000;17:408-13.

11. Camfield C, Breau L, Camfield P. Impact of pediatric epilepsy on the family: a new scale for clinical and research use. Epilepsia. 2001;42(1):104-12.

12. Mattie-Luksic M, Javornisky G, DiMario FJ. Assessment of stress in mothers of children with severe breath-holding spells. Pediatrics. 2000;106(1):1-5.

13. Setyawati L. Relation between feeling fatigue, reaction time and work productivity. J Hum Ergol. (Tokyo) 1995;24(1):129-35.

14. Chalder T, Berelowitz G, Pawlikowska T, Watts L, Wessely S, Wright D, et al. Development of a fatigue scale. J Psychosom Res. 1993;37:147-53.

15. Mclivenny S, Ahmed MH, Dunn E, Swadi H, Balshie M. The translation into Arabic and revalidation of a fatigue questionnaire. East Med Health J. 1999;5:503-14.

16. Jan MMS, Shaabat AO. Clobazam for the treatment of intractable childhood epilepsy. Saudi Med J. 2000;21(7):622-4.

17. Altman DG. Preparing to analyze data. In: Altman DG, editor. Practical Statistics for Medical Research. London: Chapman \& Hall; 1991. p. 122-51.

18. Dean AG, Dean JA, Burton A, Dicker R. Epi info: a general-purpose microcomputer program for public health information systems. Am J Prev Med. 1991;7(3):178-82.

19. Sullivan PF, Kovalenko P, York TP, Prescott CA, Kendler KS. Fatigue in a community sample of twins. Psychol Med. 2003;33(2):197-201.

20. Hein S, Bonsignore M, Barkow K, Jessen F, Ptok U, Heun R. Lifetime depressive and somatic symptoms as preclinical manifestations of late-onset depression. Eur Arch Psychiatry Clin Neurosci. 2003;253(1):16-21.

21. David A, Pelosi A, McDonald E, Stephens D, Ledger D, Rathbone $\mathrm{R}$, Mann A. Tired, weak or in need of rest: fatigue among general practice attendees. Br Med J. 1990;301: 1199-202.

22. Valdini AF, Steinhardt SI, Jaffe AS. Demographic correlates of fatigue in a university family health centre. Fam Pract. 1987;4: $103-7$.

23. Chen MK. The epidemiology of self-perceived fatigue among adults. Prev Med. 1986;15:74-81.

24. Shore CP, Austin JK, Huster GA, Dunn DW. Identifying risk factors for maternal depression in families of adolescents with epilepsy. J Spec Pediatr Nurs. 2002;7(2):71-80.

25. McQueen A, Mander R. Tiredness and fatigue in the postnatal period. J Adv Nurs. 2003;42(5):463-9.

26. Sheeran T, Marvin RS, Pianta RC. Mothers' of resolution of their child's diagnosis and self reported measures of parenting stress, marital relations, and social support. J Pediatr Psycol. 1997;22(2):197-212.

27. Kobylinska-Olak E. Prevention of inappropriate bringing up of epileptic children by their families. Neurol Neurochir Pol. 1976;10(2):225-9.

28. Otero S, Hodes M. Maternal expressed emotion and treatment compliance of children with epilepsy. Dev Med Child Neurol. 2000;42(9):604-8.

29. Butau T, Piachaud J. Knowledge and beliefs about epilepsy in mothers of children with epilepsy: a view from a developing country. Cent Afr J Med. 1993;39(9):183-8. 